Please do not remove this page

RMIT

UNIVERSITY

\title{
Talking Safety: Health and Safety Communication and Safety Climate in Subcontracted Construction Workgroups
}

Lingard, Helen; Pirzadeh, Payam; Oswald, David

https://researchrepository.rmit.edu.au/esploro/outputs/9921863403601341/filesAndLinks?institution=61RMIT_INST\&index=null

Lingard, H., Pirzadeh, P., \& Oswald, D. (2019). Talking Safety: Health and Safety Communication and Safety Climate in Subcontracted Construction Workgroups. Journal of Construction Engineering and Management, 145(5), 1-11. https://doi.org/10.1061/(ASCE)CO.1943-7862.0001651

Document Version: Accepted Manuscript

Published Version: https://doi.org/10.1061/(ASCE)CO.1943-7862.0001651

Repository homepage: https://researchrepository.rmit.edu.au

(C) ASCE

Downloaded On 2023/04/26 21:49:03 +1000

Please do not remove this page 


\title{
"Talking safety": Health and safety communication and safety climate in subcontracted construction workgroups
}

Helen Lingard ${ }^{1}$, Payam Pirzadeh ${ }^{2} \&$ David Oswald ${ }^{3}$.

\begin{abstract}
The practice of subcontracting out construction work has been identified as a contributing factor in poor work health and safety (WHS) performance. Relatively few studies have considered the processes through which safety climates develop within subcontracted workgroups. This study sought to examine the relationship between intra-group communication relating to WHS and the workgroup safety climate. Data was collected from 39 subcontracted workgroups in the Australian construction industry, using social network analysis to examine worker-to-worker, supervisor-toworker and worker-to-supervisor patterns of work health and safety (WHS) related communication. The relationship between group social network metrics and the group safety climate were examined. Network density was a predictor of the workgroup safety climate. Furthermore, a suppressor effect was found, such that WHS-related communication between group members and the group supervisor increased the variance in group safety climate explained in a regression model. The results highlight the importance of intra-group communication in creating a shared understanding about the priority placed on WHS within subcontracted construction workgroups. In using subcontracted workgroups as the unit of analysis and linking within-group communication patterns to the workgroup safety climate, the research makes an original contribution to knowledge in empirically demonstrating the safety benefits associated with fostering a dense communication network and encouraging frequent supervisor-worker communication in subcontracted workgroups.
\end{abstract}

Introduction

What is safety climate and why is it important?

Work health and safety (WHS) is understood to be influenced by aspects of the organisational environment, including team dynamics and leadership (Hofmann et al. 2017). In-keeping with this, safety climate studies are increasingly used to understand the multi-level environmental factors that impact WHS in construction organisations and projects (Gao et al., 2016).

According to Zohar (1980), safety climate consists of perceptions that workers share about their work environment that serve as a frame of reference for guiding appropriate and adaptive task behaviours. Workers observe cues in their work environment and form views about the behaviours that are prioritised and valued in their work context which then shape subsequent WHS behaviour.

Safety climate is typically measured as an individual psychological construct, an element of Zohar's definition is the degree of 'sharedness' regarding the importance of working safely in a particular work context. This sharedness develops through "ongoing social interaction in which employees

\footnotetext{
${ }^{1}$ School of Property, Construction and Project Management, RMIT University, Melbourne, Australia

2 School of Property, Construction and Project Management, RMIT University, Melbourne, Australia

${ }^{3}$ School of Property, Construction and Project Management, RMIT University, Melbourne, Australia
} 
share personal experiences informing the extent to which management cares and invests in their protection (as opposed to cost cutting or productivity)" (Hofmann et al. 2017, p.379).

Shared, positive safety climates have been linked to higher levels of WHS performance (see, for example, Beus et al. 2010a; Christian et al. 2009; Clarke, 2010, Nahrgang et al. 2011). Links between safety climate and WHS-related behaviour and performance are also reported in international studies undertaken in the construction industry (Pousette et al., 2008; Arcury et al., 2012; 2015). In a multi-wave study in a Swedish road construction project, Tholén et al. (2013) report safety climate exerted a lagged effect on workers' WHS behaviour. Importantly, this relationship was reciprocal, indicating that the creation of a virtuous safety climate-behaviour cycle could contribute to sustained continuous improvement of WHS in the construction context.

\section{Antecedents of safety climate}

While some research investigating the factors that produce strong and positive safety climates is starting to emerge (see, for example, Beus et al. 2010), this is an area in which more work is needed. Some authors have also called for greater integration of safety climate research with other management concepts and organisational phenomena, including communication, leadership and social identity (see, for example, Zohar, 2002; Andersen et al. 2018). Zohar and Tenne-Gazit (2008) investigated the extent to which transformational leadership and characteristics of intra-group communication and friendship networks predict safety climate strength in a military work context. Leaders' transformational leadership and group members' social interactions were found to predict the safety climate strength of infantry platoons. Andersen et al. (2018) also link the extent to which construction workers identify as belonging to a workgroup or project to the formation of workgroup and project safety climates respectively.

\section{Aim}

Previous research has focused extensively on the outcomes of safety climate but processes by which safety climate is formed are less well understood. The aim of this research was to understand how intra-group communication characteristics are related to safety climate within relatively small subcontracted workgroups in the construction industry. Specific objectives were:

- to ascertain whether there is a relationship between WHS-related communication initiated by supervisors and directed to work group members and the workgroup safety climate,

- to ascertain whether there is a relationship between WHS-related communication initiated by workers and directed to the workgroup supervisor and the workgroup safety climate, and

- to ascertain whether there is a relationship between member-to-member WHS-related communication and the workgroup safety climate.

A brief literature review is presented before the research methods are described and results presented and discussed. The literature positions the research in relation to:

- the link between communication and WHS outcomes,

- group-level influences on safety climate and WHS performance, and

- the ways in which communication can potentially shape workgroup safety climate and, by extension, WHS performance.

\section{Communication and work health and safety}

Effective WHS -related communication within an organisation occurs vertically (i.e. between workers and managers) and horizontally (i.e., between peers) (HSE, 2005). Open and frequent communication about WHS is important because it:

- informs workers about WHS hazards, risks and ways of working safely,

- elicits important information about workers' experiences and concerns, and 
- elicits suggestions for ways to improve WHS and facilitates joint-problem-solving (Cigularov et al., 2010; Michael et al. 2006).

Parker et al. (2001) suggest that sharing information and encouraging others to talk about the WHS aspects of their work helps workers to understand hazards and safety procedures and know when they need to apply specific WHS-related rules, for example the use of protective equipment. Open communication of WHS risk information increases trust between workers and management, while not communicating openly reduces trust (Conchie and Burns, 2008). Upward communication of WHS information also permits workers and managers to learn from errors, incidents and experiences (Hofmann and Morgeson 1999; Kath et al., 2010).

Zohar and Polachek (2014) describe how verbal exchanges between supervisors and workers play a critical role in shaping workers' perceptions about what behaviour is expected and valued. This is particularly important when complex or ambiguous messages are communicated, for example, where there is a discrepancy between an organisation's documented WHS policies and procedures and local WHS-related practices (Hollnagel, 2014). In such circumstances, communication helps workers to make sense of conflicting priorities, reduces ambiguity and provides a basis for consensus about appropriate ways of working (Zohar and Tenne-Gazit, 2008).

\section{Group level drivers of safety climate and WHS performance}

The impact of group level factors on WHS behaviour was empirically demonstrated by Simard and Marchand who report that workgroup characteristics are stronger predictors of group members' propensity to adopt WHS initiatives (Simard \& Marchand, 1995) and to comply with WHS rules (Simard \& Marchand, 1997) than organisation-level factors.

Current models of safety climate acknowledge that workers reference organisation-level, as well as group-level factors in determining the relative priority of WHS in their work environment (Zohar and Luria 2005; Hofmann et al. 2017). In the Australian construction industry, Lingard et al. (2009; 2010) demonstrated that members of subcontracted workgroups develop shared group-level safety climate perceptions that vary significantly between groups and are also independent of organisation- (i.e, principal contractor) level safety climate perceptions.

\section{Supervisors' influence on safety climate and performance}

Supervisors are also recognised to play a key role in shaping group-level safety climate perceptions as they are the planners, organisers and facilitators of daily work activities and communicate their WHS expectations to group members in a daily basis (Hardison et al. 2014; Simard \& Marchand, 1994; Choudhry and Fang, 2008).

Workers' interactions with their supervisors are more likely to have a significant impact on safety compared to senior managers because of the relative frequency of interactions (Zohar, 2002; Therkelsen and Fiebich, 2004). Fugas et al. (2011) describe how social norms develop within workgroups from informal processes of interaction between workers and their supervisors. They argue that social norms arising from group processes are more powerful, proximal and relevant to workers, and therefore more likely to produce behaviour change.

Empirical studies confirm the important role played by supervisors in the construction industry. For example, in a study of WHS performance at the London Olympic construction program, Finneran et al. (2012) identified supervisors' capabilities and competencies as a critical factor driving the effectiveness of site WHS practices. In a study of the construction industry in Finland, Mattila et al. (1994) report that workgroup WHS performance was better when foremen actively monitored workers' WHS behaviours and gave frequent feedback to workers about their work practices. In 
Denmark, Jeschke et al. (2017) found that training construction foremen in communication behaviours changed the way they interacted with workers and produced higher levels of WHSrelated cooperation and performance.

\section{Coworkers' influence on safety climate and WHS performance}

Acknowledging that safety climate and WHS performance can be influenced by people other than those in positions of formal authority, Burt et al. (2008) suggest that the extent to which group members care about their coworkers' WHS should be treated as a separate facet of the safety climate of a workgroup. Consequently, the measurement of group-level safety climate has been extended, beyond consideration of the role and influence of supervisors, to include the influence of coworkers (see, for example, Brondino et al., 2012; Lingard et al., 2011; Melia et al., 2008).

Chiaburu and Harrison (2008) suggest that it is through exchanges with coworkers that individuals develop clear beliefs about what is expected of them, i.e. what they should and should not do in their work role. Hofmann and Stetzer (1996) report that coworkers' willingness to approach a group member engaged in unsafe behaviour is a critical linking mechanism through which group processes predict WHS-related behaviour. Further, because coworkers are more likely to be perceived to be work task "experts", are closer in proximity to other workers and larger in number than supervisors, their social influence may be stronger (Tucker et al. 2008).

Brondino et al. (2012) report that safety climate arising from interactions with coworkers has a stronger effect on workers' WHS behaviour, particularly discretionary participation in WHS activities, than that arising from interactions with supervisors. Westaby and Lowe (2005) report coworker risktaking to be a stronger predictor of workers' personal risk-taking orientation than supervisory influence. Research also indicates that, especially in male-dominated workplaces, coworkers have a significant influence over group members' willingness to 'voice' WHS concerns, i.e. to communicate WHS issues upwards on the organisational hierarchy (Tucker et al. 2008; Breslin et al. 2007).

\section{Communication and group norms}

Zohar and Tenne-Gazit (2008) suggest that workgroups develop strong and coherent safety climates through an organisational socialisation process during which new workers become familiar with the accepted and expected work practices. This socialisation is believed to occur through everyday interactions between group members which lead to the establishment and acceptance of group norms (Ostroff and Kozlowski, 1992).

Hogg and Reid (2006) define group norms as "regularities in attitudes and behavior that characterize a social group and differentiate it from other social group." (p.7).

Group norms can be either descriptive (i.e, individuals' perceptions about the prevalence of a behaviour in a particular environment) or injunctive (i.e, pressures individuals experience to conform). Both types of norm can exert an influence on an individual's behaviour and group norms have been empirically linked to the WHS behaviour of subcontracted workers in construction projects (Choi et al. 2016). Previous research also suggests that the influence of group norms is strongest in the presence of ambiguity or uncertainty about what should be prioritised among competing or conflicting goals (Cialdini, 1993). Thus, when faced with a choice between working faster or safer, workers are likely to make reference to group norms.

Hofmann et al. (2017) observe how supervisors make micro-decisions every day when they translate the content of organisational policies and procedures into practical action directives. These microdecisions often occur when group members respond to conflicting objectives and inform the development of group norms relating to WHS. Zohar (2000) argues that the social interactions that take place within workgroups help workers to more accurately perceive the work environment, to 
make sense of events and develop an understanding of the behaviours that are proscribed or expected in the work environment.

Research highlights the critical role played by communication in establishing consensual group norms "...because social interaction can occur only through communication, norms cannot exist in the absence of communication among members of the group. Put another way, norms are constructed, understood, and disseminated among group members through communication" (Rimal and Real, 2003, p.185). Further, Hogg and Reid (2006) suggest that certain individuals in a group can act as central or prototypical leaders who become the focus of attention within the group because they are liked, trusted and seen as the best source of information about group norms. Hogg and Reid (2006) suggest that communication is central to prototype-based group leadership as leaders communicate their normative values, attitudes, goals, and behaviours to others.

Intra-group communication and organisational socialisation processes therefore provide one possible mechanism through which shared cognition about the importance of WHS in a work context develop. The remainder of this paper examines the link between communication and group-level safety climates in subcontracted workgroups in the construction industry.

\section{Research methods}

Data collection

Data were collected at four construction sites in metropolitan Melbourne (Australia). The sites were managed by a large construction organisation engaged in the construction of large-scale mixed use developments. Thus, potential effects of head contractor and project type were controlled via the sampling process. Data were collected from 39 participating workgroups engaged across the four sites. The distribution of workgroups by site is presented in Table 1.

Workgroup safety climate was measured using a six-item scale. Items were drawn from a larger tool that was previously developed and validated in the Australian construction industry (Lingard et al., 2014). The larger instrument was too long for use in the current study and captures perceptions of safety climate at organisational and workgroup levels, across nine dimensions of safety climate. Our analysis focused on group-level safety climate and, thus, six group-level items were chosen for use. These were selected because they reflect group members' WHS values and responsibility for self and others, which we posited would be shaped by within-group communication about WHS. Example items are: "In this workgroup, people understand the health and safety risks associated with the job," "In this workgroup, workers stop if it is dangerous to continue," and "Safe working is a condition of employment in this workgroup." Participants were asked to score the items based on their experience of working with their current workgroup. The safety climate items were scored using a five-point Likert response format ranging from " 1 = strongly disagree" to " 5 = strongly agree". 
Table 1: Participating workgroups from each site

\begin{tabular}{|l|l|l|l|}
\hline & Number of workgroups & $\begin{array}{l}\text { Mean workgroup size } \\
\text { (including supervisor) }\end{array}$ & Total participants \\
\hline Site 1 & 8 & 6.2 & 50 \\
\hline Site 2 & 8 & 7.1 & 57 \\
\hline Site 3 & 21 & 5.5 & 115 \\
\hline Site 4 & 2 & 4 & 8 \\
\hline Total & 39 & & 230 \\
\hline
\end{tabular}

Participants were also asked to identify other members of their workgroup with whom they exchange WHS-related information and to indicate the frequency with which they exchange WHSrelated information with every other member of their workgroup, including their supervisor. The frequency with which WHS-related information was given to and received from all other members was rated on a five point scale, as follows: "1=once a month," "2=bi-weekly", " $3=$ weekly," "4=once a day" and " $5=$ more than once a day." These points have previously been used in other studies using social network analysis to investigate communication in construction workgroups (e.g. Alsamadani et al. 2013). The frequency of communication was not directly entered into the regression analysis. It was, instead, used to calculate network density and centrality (which are continuous variables). Density and centrality were then entered as independent variables in the regression analysis. It is appropriate for parametric statistical methods, such as correlation and regression, to be used with Likert data with unequal distance between scales points (see Norman, 2010).

On completion of the quantitative data collection, focus groups were conducted at each participating worksite. Attendees included supervisors, site managers and worker health and safety representatives. The focus groups explored participants' perceptions of the way that communication within subcontracted workgroups shapes the workgroup safety climate and behaviour of members.

\section{Data analysis}

The internal consistency reliability of the safety climate scale was tested using Cronbach's alpha. In order to justify the aggregation of safety climate for analysis as a group-level variable within-group homogeneity was calculated according to the $r_{\text {wg }}$ formula developed by James et al. (1993). The analysis of social network data analysis involves the calculation of metrics representing characteristics of communication within a social network. Network density and centralisation were calculated (see also Zohar and Tenne-Gazit, 2008). The centrality of the workgroup supervisor was also calculated.

Network density refers to the ratio of actual links or relationships available between the network members, to the maximum possible number of links that the network can have (Borgatti \& Everett, 2006). The more the members connect with one another to exchange WHS-related information, the higher the network density will be. Hence, network density is higher when there are more WHSrelated communication ties between workgroup members and when there is higher frequency of WHS-related information exchange within these ties. Network density is calculated using the following formula:

$\Delta=\frac{L}{g(g-1)}$

where $\Delta$ is the network density, $\mathrm{L}$ is the number of existing connections, and $\mathrm{g}$ is the total number of network members (in this case, workgroup members). 
Centrality quantifies the total number of direct communication ties a network member has with other members in the network (Freeman, 1977). For the purposes of the analysis, a supervisor's centrality is the total number of communication ties that the supervisor has with workers in their workgroup. Centrality can be calculated as either in-coming or out-going. The former represents the number of direct communication ties that a supervisor has through which they provide information to other group members. The latter represents the number of direct communication ties that a supervisor has through which they receive information from other group members. The supervisors' centrality was calculated using the formula:

$C_{D}($ member $\mathrm{x})=\frac{C_{D}(\text { actor } x)}{(g-1)}$

where $C_{D}$ (member $\mathrm{x}$ ) is the total number of communication ties that the supervisor has (in or out), and $(g-1)$ is the maximum possible number of communication ties that the supervisor can have, where $g$ is the total number of network members (in this case, workgroup members).

Pearson Product Moment correlations were conducted to explore the bivariate relationships between the social network metrics and the safety climate of each workgroup. Stepwise multiple regression analyses were then performed to determine whether any of the social network metrics were predictors of the workgroup safety climate.

Prior to the application of regression analysis, tests were conducted to ensure the appropriateness of the analysis. To test the existence of a linear relationship between the independent variables (collectively) and the dependent variable, a scatterplot of the studentized residuals against the (unstandardized) predicted values was plotted. The plot indicated that the residuals formed a horizontal band, suggesting the relationship between the dependent variable and independent variables is fairly likely to be linear. Partial regression plots were used to test if a linear relationship existed between each of the independent variables and the dependent variable. The plots showed linear relationships between climate level and valued density, climate level and supervisor incentrality, and climate level and supervisor out-centrality. In addition, inspecting the scatter plot of the studentized residuals against the unstandardized predicted values indicated that the condition of homoscedasticity of residuals was met, i.e. the residuals were approximately constantly spread.

To check for multicollinearity, the correlations of the independent variables were inspected. Field (2013) suggests that the independent variables must not have correlations greater than or equal to 0.8 . No high correlation between the independent variables was identified in this study. To further confirm this, tolerance values in the regression coefficients were inspected. The values were greater than 0.1 (the lowest was 0.33 ). These results suggest that the multicollinearity is not a problem in the dataset. The standardised residuals were also inspected to detect outliers. The casewise diagnostics table, produced in SPSS, included no standardized residual greater than \pm 3 standard deviations. This suggests that there is no outlier in the dataset.

Finally, the distribution of residuals (prediction errors) was checked by developing a histogram for the residuals with a superimposed normal curve and a P-P plot. The mean and standard deviation of the residuals had values of approximately 0 (zero) and 1 (one), respectively. In addition, the P-P plot of standardized residuals confirmed that the distribution of residuals was very close to a normal distribution. As multiple regression analysis is robust against deviations from normality, no data transformation was required. These results support the use of parametric statistics (Norman, 2010). 


\section{Results}

\section{Characteristics of the sample}

Survey data was collected from 39 workgroups across four worksites between May 2017 and October 2017. A total of 154 workers and 39 supervisors participated in the data collection. At the time of data collection: 50 workers (32\%) had spent more than three months at the particular construction worksite; 34 workers (22\%) had spent between one and three months; 37 workers (24\%) between one and four weeks; and 30 workers (20\%) were in their first week at the worksite. Three workers did not respond to this question. Almost half $(18$, or $46 \%)$ of the supervisors had been on the project for more than three months. Nine supervisors $(23 \%)$ had spent between one and three months on the project; eight (20\%) between one and four weeks; and only $4(10 \%)$ were in their first week.

The duration of working in a workgroup, with a particular supervisor is theoretically and empirically linked to the climate strength, i.e. the consensus between members' perceptions of safety environment. Research evidence suggests that when employees work together for longer time, they are more likely to develop higher consensus in their perceptions of safety climate. Also, the smaller group size, the more likely that a shared understanding of safety in the work environment will develop (Zohar \& Tenne-Gazit, 2008). However, the focus of this paper was on the safety climate level (not strength), which reflects the extent to which workers perceive their immediate work environment is positively or negatively oriented towards safety. The development of climate level is theoretically more likely to be influenced by communication activity within the workgroups, rather than group size or stability of membership. Thus, between-group variation in the duration of time participants had worked together and workgroup size was not considered to be problematic for the analysis of safety climate level.

\section{Internal consistency reliability}

The Cronbach's alpha coefficient for the safety climate items was 0.84 indicating an acceptably high level of internal reliability consistency.

\section{Within-group homogeneity}

Within-group inter-rater agreement was assessed using the $r_{\mathrm{wg}}$ (James et al. 1993) to examine whether it is appropriate to aggregate the workgroup safety climate analysis and treat climate scores as a group-level variable. All 39 workgroups included in the analysis had an $r_{\mathrm{wg}}$ in excess of 0.70 , which is considered the threshold for justification of aggregation. The within-group inter-rater agreement scores for safety climate ranged from 0.85 to 1.00 . On this basis, we proceeded to treat safety climate as a group-level variable in subsequent analyses.

\section{Table 2: Workgroup characteristics and safety climate scores}

\begin{tabular}{|l|l|l|l|}
\hline Workgroup & $\begin{array}{l}\text { Size (including } \\
\text { supervisor) }\end{array}$ & $\begin{array}{l}\text { Mean safety climate } \\
\text { score (level) }\end{array}$ & $r w g$ \\
\hline 1 & 4 & 4.00 & 0.97 \\
\hline 2 & 9 & 4.22 & 0.98 \\
\hline 3 & 9 & 4.67 & 0.98 \\
\hline 4 & 4 & 4.56 & 0.95 \\
\hline 5 & 4 & 4.58 & 0.96 \\
\hline 6 & 11 & 4.54 & 0.88 \\
\hline 7 & 5 & 4.33 & 0.97 \\
\hline 8 & 4 & 4.22 & 0.86 \\
\hline
\end{tabular}




\begin{tabular}{|c|c|c|c|}
\hline 9 & 8 & 3.98 & 0.93 \\
\hline 10 & 7 & 4.28 & 0.93 \\
\hline 11 & 11 & 4.37 & 0.94 \\
\hline 12 & 9 & 4.19 & 0.98 \\
\hline 13 & 6 & 4.07 & 1.00 \\
\hline 14 & 5 & 4.33 & 0.94 \\
\hline 15 & 6 & 4.37 & 0.96 \\
\hline 16 & 5 & 4.38 & 0.97 \\
\hline 17 & 4 & 4.56 & 0.97 \\
\hline 18 & 6 & 4.46 & 0.87 \\
\hline 19 & 4 & 4.89 & 0.99 \\
\hline 20 & 5 & 4.04 & 0.95 \\
\hline 21 & 4 & 4.39 & 0.99 \\
\hline 22 & 5 & 4.25 & 0.96 \\
\hline 23 & 6 & 5.00 & 1.00 \\
\hline 24 & 6 & 4.33 & 0.96 \\
\hline 25 & 6 & 4.03 & 0.93 \\
\hline 26 & 6 & 4.33 & 0.95 \\
\hline 27 & 8 & 4.33 & 0.98 \\
\hline 28 & 7 & 4.67 & 0.97 \\
\hline 29 & 6 & 4.71 & 0.98 \\
\hline 30 & 4 & 4.78 & 0.98 \\
\hline 31 & 9 & 4.57 & 0.94 \\
\hline 32 & 4 & 3.89 & 0.95 \\
\hline 33 & 4 & 4.39 & 0.94 \\
\hline 34 & 6 & 4.58 & 0.98 \\
\hline 35 & 4 & 4.61 & 0.97 \\
\hline 36 & 5 & 4.67 & 0.97 \\
\hline 37 & 6 & 4.83 & 0.99 \\
\hline 38 & 5 & 4.71 & 0.97 \\
\hline 39 & 3 & 4.75 & 0.98 \\
\hline
\end{tabular}

\section{Bivariate correlations}

Table 3 presents the bivariate correlations between the social network measures and safety climate. As the analysis indicated, higher values of communication density in workgroups were correlated with a more positive safety climate $(r=.336, p=.036, N=39)$. In addition, there were positive and significant correlations between the social network measures, i.e. a positive correlation between valued density and supervisor's in-centrality $(r=.705, p<.01, N=39)$, between valued density and supervisor's out-centrality $(r=.564, p<.01, N=39)$ and between supervisor's in-centrality and supervisor's out-centrality $(r=.747, p<.01, N=39)$. However, no significant correlation was identified between the safety climate and any of the supervisors' centrality measures (in- and outcentrality).

Table 3: Bivariate correlations between safety climate and workgroup social network metrics

\begin{tabular}{|l|l|l|l|l|}
\hline & $\begin{array}{l}\text { Valued } \\
\text { density }\end{array}$ & $\begin{array}{l}\text { Supervisor in- } \\
\text { centrality }\end{array}$ & $\begin{array}{l}\text { Supervisor out- } \\
\text { centrality }\end{array}$ & $\begin{array}{l}\text { Safety } \\
\text { climate }\end{array}$ \\
\hline Valued density & 1 & & & \\
\hline $\begin{array}{l}\text { Supervisor in- } \\
\text { centrality }\end{array}$ & $.705^{* *}$ & 1 & & \\
\hline
\end{tabular}




\begin{tabular}{|l|l|l|l|l|}
\hline $\begin{array}{l}\text { Supervisor out- } \\
\text { centrality }\end{array}$ & $.564^{* *}$ & $.747^{* *}$ & 1 & \\
\hline Safety climate & $.336^{*}$ & .079 & .286 & 1 \\
\hline
\end{tabular}

$* *$. Correlation is significant at the 0.01 level (2-tailed)

*. Correlation is significant at the 0.05 level (2-tailed

\section{Regression analysis}

Multiple regression analysis was used to further investigate whether the social network measures significantly predicted safety climate. Different combinations of the predictor variables were explored in four models. The results are presented in Table 4.

The valued density of workgroup WHS communication ties was a significant predictor of workgroup safety climate explaining $8.9 \%$ of the variance in workgroup safety climate scores (model 1 ). The inclusion of supervisors' in-centrality (in model 2) slightly improved the ability of the model to explain the variance in workgroup safety climate (as indicated by the slight improvement in the value for adjusted $\mathrm{R}^{2}$ from $8.9 \%$ in model 1 to $11.6 \%$ in model 2 ). However, supervisors' in-centrality was not a significant predictor of workgroup safety climate in model 2 . The inclusion of supervisors' out-centrality (in model 3 ) did not improve the adjusted $\mathrm{R}^{2}$ and nor was supervisors' out-centrality a significant predictor of workgroup safety climate in model 3 .

In addition, regression analyses testing the relationship between the safety climate and each of the supervisor's centrality measures (in- and out-centrality) did not indicate any significant results, as expected from the bivariate correlation results. The two centrality variables were also added together to create a new variable reflecting the supervisor's overall centrality in the communication networks. The safety climate level was then regressed on this new variable and no significant relationship was identified.

However, to test the combined effect of the social network measures on safety climate, the valued density and supervisors' in- and out-centrality measures were included in a final regression analysis (model 4). The results of this combined regression analysis indicated that, together, the social network metrics explained $19.4 \%$ of the variance on workgroup safety climate. In addition, measures of supervisors' centrality (i.e. both in-centrality and out-centrality) as well as the valued density of within-group WHS communication ties significantly predicted the workgroup safety climate. The inclusion of supervisors' centrality metrics in the regression model also increased the regression coefficient for the valued density of within-group communication ties. Thus, even though supervisors' in- and out-centrality were not significantly correlated with the workgroup safety climate when considering bivariate relationships, the overall regression model suggests that supervisors' in- and out-centrality are still relevant in terms of the formation of workgroup safety climates. The inclusion of supervisors' in- and out- centrality in model 4 increased the adjusted $\mathrm{R}^{2}$ from 0.089 (when only the valued density of WHS-related communication ties was included in model 1) to 0.194 in model 4 . Thus, the inclusion of supervisors' in- and out-centrality appears to strengthen the positive effect of the valued density of WHS communication on the workgroup safety climate.

Table 4: Regression analyses

\begin{tabular}{|l|l|l|l|l|l|l|l|l|}
\hline Model & Predictors & Adjusted R square & F & Sig. & \multicolumn{4}{|c|}{ Coefficients } \\
\cline { 3 - 8 } & & & & B & SE & B & Sig. \\
\hline Model & Constant & .089 & 4.712 & .036 & 4.243 & .097 & & .000 \\
\hline
\end{tabular}




\begin{tabular}{|c|c|c|c|c|c|c|c|c|}
\hline 1 & Network valued density & & & & .399 & .184 & .336 & .036 \\
\hline \multirow{3}{*}{$\begin{array}{l}\text { Model } \\
2\end{array}$} & Constant & \multirow[t]{3}{*}{.116} & \multirow[t]{3}{*}{3.487} & \multirow[t]{3}{*}{.041} & 4.283 & .099 & & .000 \\
\hline & Network valued density & & & & .660 & .255 & .557 & .014 \\
\hline & Supervisor's in-centrality & & & & -.233 & 160 & $\begin{array}{l}- \\
.313\end{array}$ & .154 \\
\hline \multirow{3}{*}{$\begin{array}{l}\text { Model } \\
3\end{array}$} & Constant & \multirow[t]{3}{*}{.078} & \multirow[t]{3}{*}{2.606} & \multirow[t]{3}{*}{.088} & 4.182 & .127 & & .000 \\
\hline & Network valued density & & & & 305 & .224 & 257 & .182 \\
\hline & $\begin{array}{l}\text { Supervisor's out- } \\
\text { centrality }\end{array}$ & & & & .127 & 170 & 141 & .461 \\
\hline \multirow{4}{*}{$\begin{array}{l}\text { Model } \\
4\end{array}$} & Constant & \multirow[t]{4}{*}{.194} & \multirow[t]{4}{*}{4.055} & \multirow[t]{4}{*}{.014} & 4.123 & 121 & & .000 \\
\hline & Network valued density & & & & .619 & .244 & .521 & .016 \\
\hline & Supervisor's in-centrality & & & & -.474 & 190 & -636 & .018 \\
\hline & $\begin{array}{l}\text { Supervisor's out- } \\
\text { centrality }\end{array}$ & & & & .42 & .198 & .466 & .041 \\
\hline
\end{tabular}

These results suggest a suppressor situation (Horst, 1941; Cohen et al., 2003). In a classic suppressor situation, a variable which is not correlated with the dependent (outcome) variable, but is correlated with a predictor variable in the model, suppresses some of the variance in the predictor and improves the predictability of the model and the effect of the predictor. This improvement takes place because the suppressed variance in the predictor is irrelevant to the dependent (outcome) variable. In this study, it is possible that the supervisors' centrality measures and the valued density of communication ties mutually suppressed a portion of one another's variance that was unrelated to the workgroup safety climate, improving the predictive ability of both valued density and supervisors' centrality in regression model 4 . Consequently, the adjusted $\mathrm{R}^{2}$ and the coefficients for the predictor variables were greater in model 4 than in model 1 . This suppressor effect was not observed in models 2 and 3, which included only one of the supervisors' centrality measures (i.e. model 2 only included supervisor's in-centrality and model 3 included only supervisor's outcentrality). The suppression effect was only observed when both of the supervisors' centrality measures (i.e, in- and out-centrality) were included in the model along with the valued density of network WHS communication ties.

\section{Discussion}

Within-group WHS communication and safety climate

In this study, valued network density represents the presence of WHS-related communication ties between workgroup members (as a proportion of the possible ties in a workgroup) and the frequency of WHS-related information exchange within these ties (represented in Figure 1). 
Figure 1: Example workgroups with high compared to low network valued density

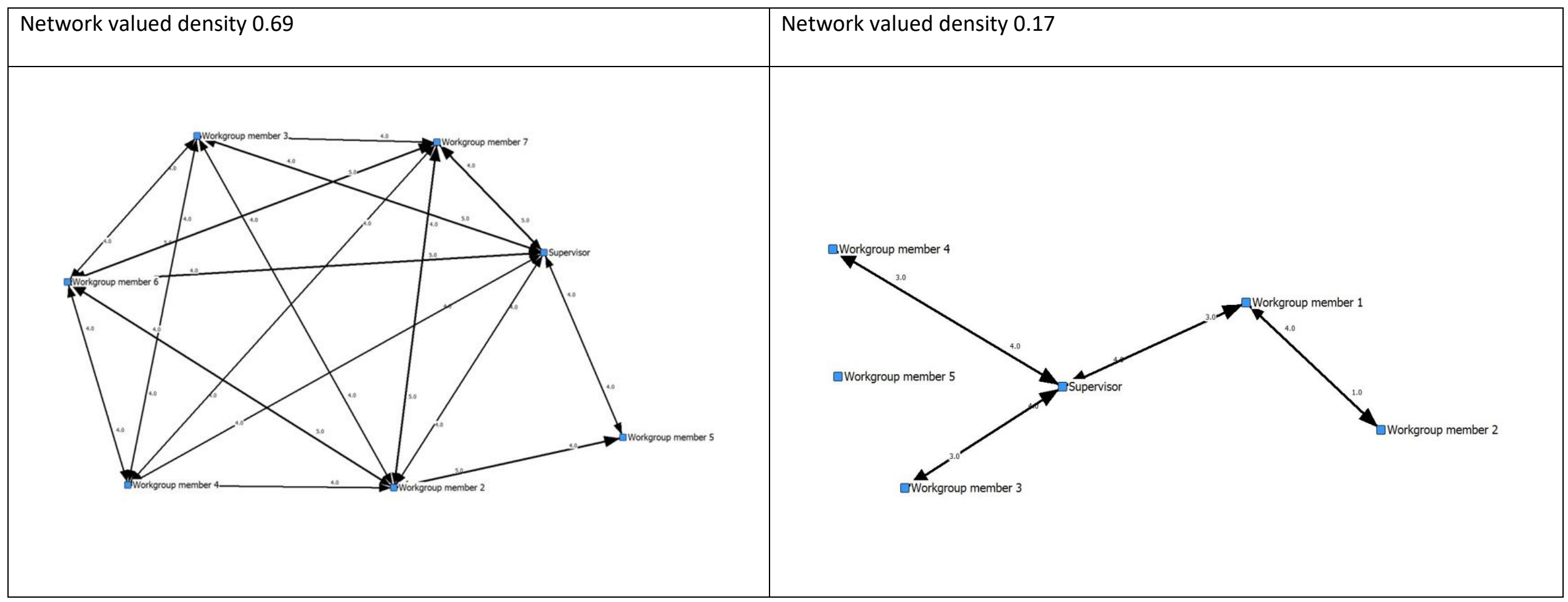


Valued density captures the extent and frequency of WHS-related communication that occurs between the supervisor and all other members of each workgroup (i.e, worker-to-supervisor and supervisor-to-worker communication), as well as the frequency of WHS-related communication that occurs between the workers who make up each workgroup and all other worker members of the group (i.e., coworker-to-coworker communication). The bivariate correlation results, as well as the regression results (models 1 and 2), reveal that the valued density of the workgroup communication networks is positively linked to the workgroup safety climate. Thus, the greater the extent and frequency of WHS-related communication between all members of a workgroup social network (including the supervisor), the more positive the safety climate will be. This finding is consistent with previous research that has linked communication with WHS outcomes (Parker et al. 2001; Vredenburgh, 2002; Zacharatos et al. 2005). Parker et al. (2001) suggest that communication provides workers with information that they need to work safely. Michael et al. (2006) similarly report that freely discussing WHS issues under routine and non-routine operating conditions provides a shared understanding of expected behaviours and how procedures should be translated into work practices.

Interpreting the suppression effect - the importance of coworker-to-coworker communication Neither supervisor in-centrality nor supervisor out-centrality was significantly related to the workgroup safety climate in the bivariate correlation analysis, nor were they significant predictors of safety climate when included by themselves in a regression model (models 2 and 3 ). However, the regression analysis revealed a suppression effect, whereby the inclusion of both supervisors' centrality metrics (i.e. in- and out-centrality) in the regression model strengthened the predictive effect of the valued density of the workgroups' communication network on the workgroup safety climate. Further, when included alongside the valued density of the network both supervisors' inand supervisors' out-centrality were significant predictors.

Understanding suppression effects in multiple regression is important in reaching conclusions that would not be reached if independent variables with non-significant bivariate relationships with the dependent variable were eliminated from a regression analysis (Lancaster, 1999). Statisticians caution against eliminating predictor variables that are not significantly related to outcome variables at the bivariate level, arguing that bivariate correlation coefficients are an ill-suited method for selecting variables to include in a multiple regression model (Pandey and Elliott, 2010). Pandey and Elliott (2010) argue that eliminating uncorrelated variables that are theoretically linked to the dependent variable can undermine the predictive power of a regression model and yield regression equations which are overly sample-specific. It is therefore recommended that, to accurately understand the contribution of all theoretically relevant independent variables, all of these variables should be included in the regression model, irrespective of whether they demonstrated nonsignificant bivariate correlations with the dependent variable (Lancaster, 1999). Thus, supervisors' in- and out-centrality in the workgroup communication network appeared to be unimportant in analysis conducted at the bivariate level, yet made a substantial contribution to the multivariate regression model.

Because valued density captures the extent and frequency of worker-to-supervisor and supervisorto-worker communication, as well as coworker-to-coworker communication, one interpretation of this suppression effect is that although, in model 1, the predictive ability of the network's valued density on the workgroup safety climate was significant, this effect may have been reduced because of the supervisor's high centrality in the communication network of some workgroups. Thus, including supervisors' centrality in the subsequent regression model (model 4) suppressed the variance on the network density explained by supervisors' centrality and improved the predictive ability of the regression model. 
When supervisors' centrality (both in- and out-centrality) was included in the model, the overlapping effects of network density and supervisors' centrality were reduced producing a clearer predictive model of workgroup safety climate. Consequently, the stronger and more significant effect for network density in model 4 reflects the strong contribution that the coworker-to-coworker communication makes to the development of workgroup safety climates, above and beyond the effects of worker-to-supervisor and supervisor-to worker communication. This was supported by comments from supervisors who participated in focus groups as part of the research. One supervisor explained: " [workers] have lots of opportunities apart from being one on one with us, when we're all sitting down they can all discuss, say 'I've got this issue, do you guys have this issue?' 'Yeah, that's what I've had happen to me too' and we try and resolve it between ourselves. 'Cos we get together as a group so many times, so often, that most problems get resolved by the workers just talking to each other. I'm just sitting there listening, 'you guys sort it all out, let's document it...cause we're sitting down so often on a regular basis that if they do have an issue they can work out, 'on this job we did this and we sorted it out that way', 'oh okay'. They're the guys doing the work and most of the guys have done the work somewhere where they've had something go wrong, and they sort it out themselves."

The importance of coworker-to-coworker communication about WHS in both statistical analysis and the comments made by supervisors indicates that norms relating to WHS are likely to extend beyond the influence of dyadic relationships, such as that between a supervisor and a worker, to include members of the broader workgroup.

This finding is consistent with previous research identifying the role played by coworkers in the development of safe and healthy workgroup climates. For example, Zhou et al. (2008) found construction workers' safety behaviour to be more sensitive to normative influences from coworkers than directions given through formal WHS training or through interactions with managers.

\section{Supervisors' WHS communication and safety climate}

The results also suggest that the association between communication that occurs between the supervisor and all other members of each workgroup (i.e, worker-to-supervisor and supervisor- toworker communication) and the workgroup safety climate is not straightforward.

The inclusion of the supervisors' centrality measures, together with network density in the model, also resulted in significant and improved effects for both supervisor's in- and out-centrality.

However, no significant effect was observed when supervisors' centrality measures were included in the model (either separately or in combination) without the inclusion of network density. These results indicate that the effect of supervisors' centrality on the workgroup safety climate is significant but is distinct from that of the general (coworker-to-coworker) network communication. In the correlation analysis and regression models 2 and 3, the effect of supervisors' centrality on the workgroup safety climate was masked by the effect of network density on the safety climate and only became evident when the communication density was controlled for in model 4 .

It is noteworthy that the effect of supervisors' in- and out- centrality on the workgroup safety climate was found to be in opposite directions. That is, the effect on the workgroup safety climate was positive for the supervisors' out-centrality (See Figure 2) and was negative for supervisors' incentrality. 
Figure 2: Example workgroups with high compared to low supervisor out-centrality

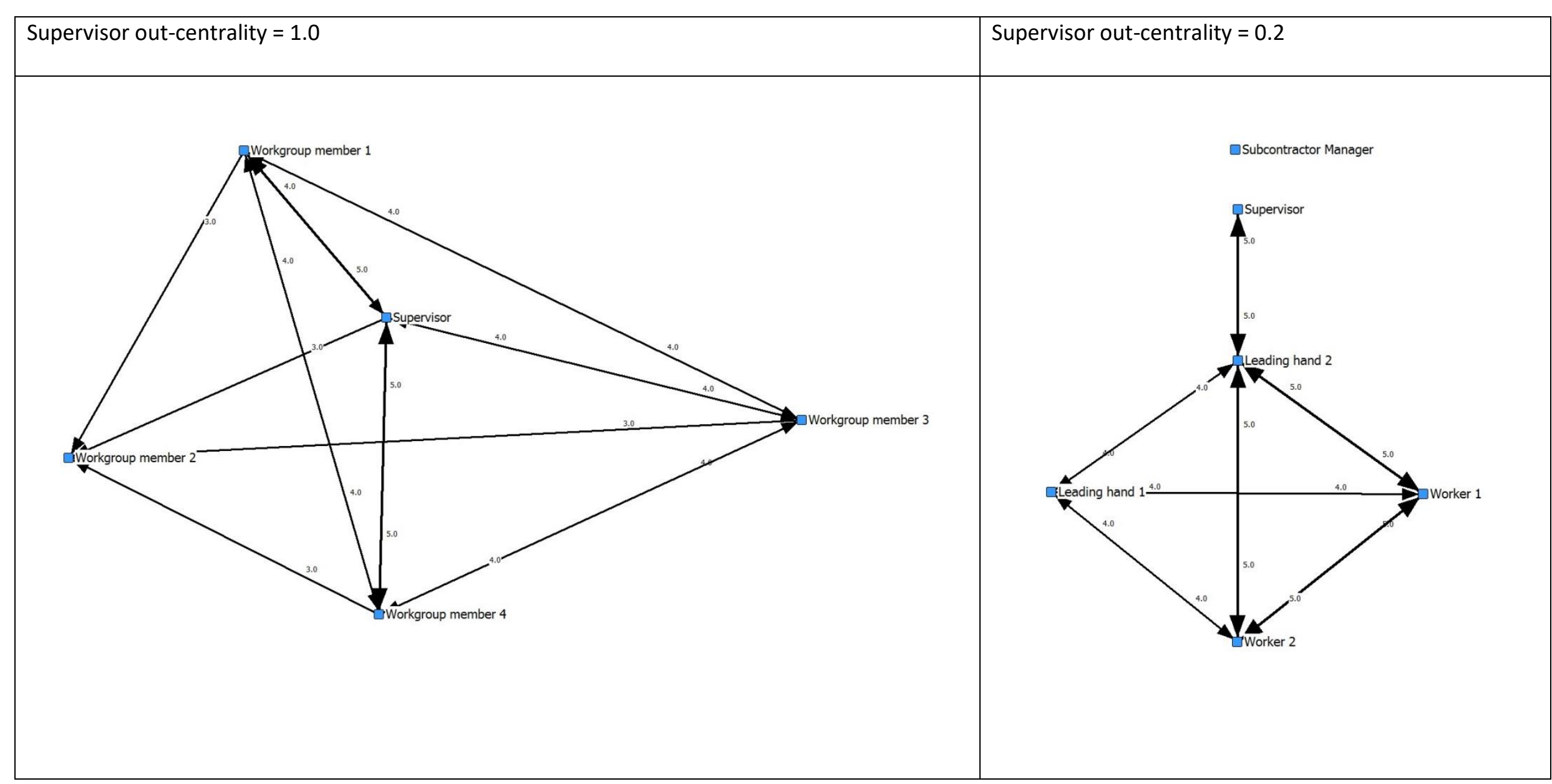


The positive relationship between supervisors' outgoing WHS-related communication with workers about WHS is consistent with previous research which shows how communication from supervisors to workers is particularly important in establishing social norms about expected behaviours, that are particularly important in non-routine situations, or where there is ambiguity about which facet of performance should be prioritised, or where there is a discrepancy between work as imagined and work as done (Zohar and Tenne-Gazit, 2008).

The negative relationship between supervisors' in-flowing WHS-related communication and the workgroup safety climate was unexpected because previous research has linked workers' 'voice' behaviour to the existence of a positive safety climate, i.e., the safety climate is positioned as an antecedent to workers' willingness to raise WHS concerns (see, for example Hofmann \& Morgesen, 1999). However, Kath et al. (2010) found that the communication of WHS concerns from workers to supervisors is more likely to occur when workers perceive that there is greater conflict between working safely and meeting production goals. Therkelsen and Fiebich (2004) similarly suggest that WHS-related communication workers to supervisors is likely to be negative because people are more likely to communicate dislikes upwards within an organisation. This was supported by comments made by a site manager in the focus groups conducted as part of the research who explained: "when the workers are out there, and it's a nice sunny day, and everything is going to plan there's no need for them to talk to their supervisors. You just get on with your job, you're happy. But when it's raining, there's water everywhere, and your work is unclean, you know messy, sh*t everywhere, the workers are complaining to the supervisors or communicating, saying 'well this isn't right, I'm not happy with this'...So [there is] more communication from the workers to the supervisor if the job is not at a high quality safety standard."

The communication of WHS concerns or problems from workers to supervisors is not necessarily a bad thing. Therkelsen and Fiebich (2004) argue that upward negative feedback should be encouraged because it provides management with opportunities to learn about and correct WHS problems (Therkelsen and Fiebich, 2004). Future longitudinal research should consider the direction of the relationship between the communication of WHS concerns and the workgroup safety climate, as well as the role played by the supervisors' response to the communication of concerns. It is possible that when supervisors respond positively to address workers' safety concerns, this will have a positive impact on the workgroup safety climate at a subsequent point in time.

\section{Theoretical implications of the research}

Previous research has examined the role of workgroup-level safety climates on WHS performance but, most of this research has focused on the measurement of safety climate or safety climate outcomes. Relatively less attention has been paid to the important question of how safety climates form. The current research provides preliminary evidence to link communication patterns within subcontracted workgroups in the construction industry with workgroup safety climates. Michael et al. (2006) suggest that, although communication is important, communication needs to be considered as part of a larger picture of organisational and workgroup safety climates and indications of management commitment.

The consideration of communication processes in norm-based theories of safety climate potentially enable a new insight into the way that (i) workgroup climates are formed and maintained, (ii) group norms become socially accepted, (iii) group members' WHS behaviour is ultimately influenced (Lapinski \& Rimal, 2005).

\section{Practical implications of the research}

The research highlights the practical importance of communication in promoting WHS performance through the establishment of group norms relating to expected WHS behaviours. The research 
suggests that communication patterns within workgroups, in particular the density of communication ties and supervisors' WHS-related communication with workers are important for the development of positive workgroup safety climates. Clarke and Ward (2006) describe how supervisors can use persuasive communication, logical argument and factual evidence to encourage subordinates' WHS behaviour. Willis et al. (2017) also argue that good quality communication is particularly important in unpredictable safety-critical environments. In these contexts, effective communication reduces ambiguity and helps workers to make sense of the situations they encounter in their work.

The importance of WHS-related communication for the development of positive safety climates suggests that strategies to improve the frequency and also the quality of communication relating to WHS within workgroups may be beneficial. Therkelson \& Fiebich (2004) point out that supervisors are not always effective communicators and therefore developing communication capability may be needed. Strategies could include training and actively recognising supervisors' WHS communication practices (see, for example Kines et al. 2010) or designing work schedules to allow time for work group members to share WHS information and ideas.

\section{Conclusions}

The research used social network analysis in a sample of 39 subcontracted workgroups to examine the relationship between WHS-related communication patterns and workgroup safety climates. The research found significant relationships between within-group communication patterns and the prevailing workgroup safety climate. In particular, high valued density in a workgroup's communication network, indicating a high proportion of active communication ties and frequent information exchanges, was significantly and positively linked to the workgroup's safety climate. An unexpected suppressor effect was also evident, whereby supervisors' WHS-related communication with workers was not significantly related to the workgroup safety climate in bivariate correlation analysis but, when included in a regression model, enhanced the ability of network communication density to predict the workgroup safety climate. When included in the full regression model, supervisors' communication activities were also significant predictors of the workgroup safety climate. The research provides important new insights into the role of communication in forming workgroup level safety climates, which can influence members' WHS-related behaviour. In using subcontracted workgroups as the unit of analysis and linking within-group communication patterns to the workgroup safety climate, the research makes an original contribution to knowledge in empirically demonstrating the safety benefits associated with fostering a dense communication network and encouraging frequent supervisor-worker communication in subcontracted workgroups.

\section{Limitations and future research}

The research was limited in its cross-sectional design, which does not permit an analysis of causality. Thus, it is not possible to rule out reverse causality, i.e. that positive group safety climates are the antecedent to frequent and prevalent WHS-related communication within workgroups. The research was also limited to a single, albeit large, construction organisation working in a specific sub-sector of the construction industry in a limited geographical area. Future research should examine whether the relationship between workgroup WHS-related communication characteristics and safety climate are observed in other organisations, industry sectors or geographic locations. Finally, the research did not consider the issue of stability/instability turnover in group membership. Future research could focus on the role played by stability of membership and the relationship between communication and safety climate. 


\section{Acknowledgement}

This research was funded by Lendlease.

\section{References}

Alsamadani, R., Hallowell, M., \& Javernick-Will, A. (2013). Measuring and modelling safety communication in small work crews in the US using social network analysis. Construction Management and Economics, 31(6), 568-579.

Andersen, L. P., Nørdam, L., Joensson, T., Kines, P., \& Nielsen, K. J. (2018). Social identity, safety climate and self-reported accidents among construction workers. Construction Management and Economics, 36(1), 22-31. Arcury, T. A., Mills, T., Marín, A. J., Summers, P., Quandt, S. A., Rushing, J., \& Grzywacz, J. G.

(2012). Work safety climate and safety practices among immigrant Latino residential construction workers. American Journal of Industrial Medicine, 55(8), 736-745.

Arcury, T. A., Summers, P., Rushing, J., Grzywacz, J. G., Mora, D. C., Quandt, S. A., \& Mills, T. H. (2015). Work safety climate, personal protection use, and injuries among Latino residential roofers. American Journal of Industrial Medicine, 58 (1), 69-76.

Beus JM, Payne SC, Bergman ME, Arthur W Jr. 2010a. Safety climate and injuries: an examination of theoretical and empirical relationships. Journal of Applied Psychology, 95:713-27

Beus JM, Bergman ME, Payne SC. 2010b. The influence of organizational tenure on safety climate strength: a first look. Accident Analysis and Prevention. 42:1431-7

Borgatti, S. P. \& Everett, M. G. (2006). A Graph-theoretic perspective on centrality. Social Networks, 28(4), 466484.

Breslin, F.C., Polzer, J., MacEachen, E., Morrongiello, B. \& Shannon, H. (2007), Workplace injury or 'part of the job'? Towards a gendered understanding of injuries and complaints among young workers, Social Science and Medicine, 64, 782-93.

Brondino, M., Silva, S. A., \& Pasini, M. (2012). Multilevel approach to organizational and group safety climate and safety performance: Co-workers as the missing link. Safety Science, 50(9), 1847-1856.

Burt, C.D.B., Sepie, B. \& McFadden, G. (2008), The development of a considerate and responsible safety attitude in work teams, Safety Science, 46, 79-91.

Chiaburu, D.S. \& Harrison, D.A. (2008), Do peers make the place? Conceptual synthesis and meta-analysis of coworker effects on perceptions, attitudes, OCBs and performance, Journal of Applied Psychology, 93, 1082103.

Choi, B., Ahn, S., \& Lee, S. (2016). Role of social norms and social identifications in safety behavior of construction workers. I: Theoretical model of safety behavior under social influence. Journal of Construction Engineering and Management, 143(5), 04016124.

Choudhry, R.M. and Fang, D. (2008) Why operatives engage in unsafe work behavior: investigating factors on construction sites. Safety Science, 46(4), 566-84.

Christian MS, Bradley JC, Wallace JC, \& Burke MJ. 2009. Workplace safety: a meta-analysis of the roles of person and situation factors. Journal of Applied Psychology. 94:1103-27

Cialdini, R. C. (1993). Influence: Science and practice (3rd ed.). New York: HarperCollins.

Cigularov, K. P., Chen, P. Y., \& Rosecrance, J. (2010). The effects of error management climate and safety communication on safety: A multi-level study. Accident Analysis \& Prevention, 42(5), 1498-1506.

Clarke, S. (2010). An integrative model of safety climate: Linking psychological climate and work attitudes to individual safety outcomes using meta-analysis. Journal of Occupational and Organizational Psychology,83(3), 553-578.

Clarke, S., \& Ward, K. (2006). The role of leader influence tactics and safety climate in engaging employees' safety participation. Risk Analysis, 26(5), 1175-1185.

Cohen, J., Cohen, P., West, S. G., \& Aiken, L. S. (2003). Applied multiple regression/correlation analysis for the behavioral sciences. Mahwah, NJ: Lawrence Erlbaum.

Conchie, S. M., \& Burns, C. (2008). Trust and risk communication in high-risk organizations: a test of principles from social risk research. Risk Analysis, 28(1), 141-149.

Freeman, L. C. (1977). A Set of Measures of Centrality Based on Betweenness. Sociometry, 4O(1), 35-41.

Fugas, C. S., Meliá, J. L., \& Silva, S. A. (2011). The "is" and the "ought": How do perceived social norms influence safety behaviors at work? Journal of Occupational Health Psychology, 16(1), 67-79. 
Gao, R., Chan, A. P., Utama, W. P., \& Zahoor, H. (2016). Multilevel safety climate and safety performance in the construction industry: Development and validation of a top-down mechanism. International Journal of Environmental Research and Public Health, 13(11), 1100. https://doi.org/10.3390/ijerph13111100

Guo, B. H., Yiu, T. W., \& González, V. A. (2016). Predicting safety behavior in the construction industry: Development and test of an integrative model. Safety Science, 84, 1-11.

Hardison, D., Behm, M., Hallowell, M. R., \& Fonooni, H. (2014). Identifying construction supervisor competencies for effective site safety. Safety Science, 65, 45-53.

Health and Safety Executive (2005), Development and validation of the HMRI safety culture inspection toolkit, Research Report 365, HSE Books, London.

Hofmann, D.A. \& Stetzer, A. (1996), A cross-level investigation of factors influencing unsafe behaviours and accidents, Personnel Psychology, 49, 307-39.

Hofmann, D. A., \& Morgeson, F. P. (1999). Safety-related behavior as a social exchange: The role of perceived organizational support and leader-member exchange. Journal of Applied Psychology, 84(2), 286.

Hofmann, D. A., Burke, M. J., \& Zohar, D. (2017). 100 years of occupational safety research: From basic protections and work analysis to a multilevel view of workplace safety and risk. Journal of Applied Psychology, 102(3), 375-388.

Hogg, M. A., \& Reid, S. A. (2006). Social identity, self-categorization, and the communication of group norms. Communication Theory, 16(1), 7-30.

Hollnagel, E. (2014). Safety-I and safety-ll: the past and future of safety management. Ashgate Publishing, Ltd. Horst, P. (1941). The prediction of personal adjustment. Social Science Research Council Bulletin, 48. New York, NY: Social Science Research Council

James, L. R., Demaree, R. G., \& Wolf, G. (1993). Rwg: An assessment of within-group interrater agreement. Journal of Applied Psychology, 78, 306-309.

Jeschke, K. C., Kines, P., Rasmussen, L., Andersen, L. P. S., Dyreborg, J., Ajslev, J., ... \& Andersen, L. L. (2017). Process evaluation of a Toolbox-training program for construction foremen in Denmark. Safety Science, 94, 152-160

Kath, L. M., Marks, K. M., \& Ranney, J. (2010). Safety climate dimensions, leader-member exchange, and organizational support as predictors of upward safety communication in a sample of rail industry workers. Safety Science, 48(5), 643-650.

Kines, P., Andersen, L. P., Spangenberg, S., Mikkelsen, K. L., Dyreborg, J., \& Zohar, D. (2010). Improving construction site safety through leader-based verbal safety communication. Journal of Safety Research,41(5), 399-406.

Lancaster, B. P., (1999), Defining and Interpreting Suppressor Effects: Advantages and Limitations, Paper presented at the Annual Meeting of the Southwest Educational Research Association (San Antonio, TX, January 21-23, 1999).

Lingard, H., Cooke, T. \& Blismas, N., (2009) Group-level safety climate in the Australian construction industry: Within-group homogeneity and between-group differences in road construction and maintenance. Construction Management and Economics, 27, 419-432.

Lingard, H., Cooke T. \& Blismas, N., (2010), Safety climate in conditions of construction subcontracting: A multilevel analysis. Construction Management and Economics, 28, pp. 313-825.

Lingard, H., Cooke, T. \& Blismas, N., (2011), Coworkers' response to occupational health and safety: An overlooked dimension of group-level safety climate in the construction industry? Engineering, Construction and Architectural Management, 18, 159-175.

Lingard, H., Zhang, R., Harley, J., Blismas, N. \& Wakefield, R., (2014), Health and Safety Culture, Australian Constructors Association/RMIT University, Sydney.

Melia, J.L., Mearns, K., Silva, S.A. and Lima, M.L. (2008), Safety climate responses and the perceived risk of accidents in the construction industry, Safety Science, 46, 949-58.

Michael, J. H., Guo, Z. G., Wiedenbeck, J. K., \& Ray, C. D. (2006). Production supervisor impacts on subordinates' safety outcomes: An investigation of leader-member exchange and safety communication. Journal of Safety Research,37(5), 469-477.

Nahrgang, J. D., Morgeson, F. P., \& Hofmann, D. A. (2011). Safety at work: A meta-analytic investigation of the link between job demands, job resources, burnout, engagement, and safety outcomes. Journal of Applied Psychology, 96, 71-94.

Norman, G. (2010). Likert scales, levels of measurement and the 'laws' of statistics. Advances in Health Science Education, 15 (5), 625-632.

Ostroff, C., \& Kozlowski, S. W. (1992). Organizational socialization as a learning process: The role of information acquisition. Personnel Psychology, 45(4), 849-874. 
Pandey, W., \& Elliott, S. (2010). Suppressor variables in social work research: Ways to identify in multiple regression models. Journal of the Society for Social Work and Research, 1, 28-40.

Pousette, A., Larsson, S. \& Törner, M. (2008), Safety climate cross-validation, strength and

prediction of safety behaviour, Safety Science, Vol. 46, pp. 398-404.

Pryke, S. (2012). Social network analysis in construction: John Wiley \& Sons.

Rimal, R. N., \& Real, K. (2003). Understanding the influence of perceived norms on behaviors. Communication Theory, 13(2), 184-203.

Simard, M., \& Marchand, A. (1994). The behaviour of first-line supervisors in accident prevention and effectiveness on occupational safety. Safety Science, 17, 169-185.

Simard, M., \& Marchand, A. (1995). A multi-level analysis of organisational factors related to the taking of safety initiatives by work groups. Safety Science, 21, 113-129.

Simard, M., \& Marchand, A. (1997). Workgroups' propensity to comply with safety rules: The influence of micromacro organisational factors. Ergonomics, 40, 172-188.

Therkelsen, D. J., \& Fiebich, C. L. (2004). The supervisor: The linchpin of employee relations. Journal of Communication Management, 8(2), 120-129.

Tholén, S. L., Pousette, A., \& Törner, M. (2013). Causal relations between psychosocial conditions, safety climate and safety behaviour-A multi-level investigation. Safety Science,55, 62-69.

Tucker, S., Chmiel, N., Turner, N., Hershcovis, M.S. and Stride, C.B. (2008), Perceived organizational support for safety and employee safety voice: the mediating role of co-worker support for safety", Journal of Occupational Health Psychology, 13, 319-30.

Vredenburgh, A. G. (2002). Organizational safety: which management practices are most effective in reducing employee injury rates? Journal of Safety Research, 33(2), 259-276.

Willis, S., Clarke, S., \& O'Connor, E. (2017). Contextualizing leadership: Transformational leadership and Management-By-Exception-Active in safety-critical contexts. Journal of Occupational and Organisational Psychology. 1-25.

Zacharatos, A., Barling, J., \& Iverson, R. D. (2005). High performance work systems and occupational safety. Journal of Applied Psychology, 90, 77-93.

Zhou, Q., Fang, D.P. \& Wang, X. (2008), A method to identify strategies for the improvement of human safety behavior by considering safety climate and personal experience, Safety Science, Vol. 46, pp. 1406-19

Zohar, D. (1980). Safety climate in industrial organizations: theoretical and applied implications. Journal of Applied Psychology, 65(1), 96-102

Zohar, D. (2000). A group-level model of safety climate: testing the effect of group climate on microaccidents in manufacturing jobs. Journal of Applied Psychology, 85(4), 587.

Zohar, D., \& Luria, G. (2005). A multilevel model of safety climate: Cross-level relationships between organization and group-level climates. Journal of Applied Psychology, 90, 616-628

Zohar, D., \& Tenne-Gazit, O. (2008). Transformational leadership and group interaction as climate antecedents: a social network analysis. Journal of Applied Psychology,93(4), 744.

Zohar, D., \& Polachek, T. (2014). Discourse-based intervention for modifying supervisory communication as leverage for safety climate and performance improvement: A randomized field study. Journal of Applied Psychology, 99(1), 113.

Zohar, D., \& Luria, G. (2010). Group leaders as gatekeepers: Testing safety climate variations across levels of analysis. Applied Psychology, 59(4), 647-673.

Zohar, D. (2002). Modifying supervisory practices to improve subunit safety: a leadership-based intervention model. Journal of Applied Psychology, 87(1), 156. 